\title{
In situ heart valve tissue engineering: Using the innate immune response to do the hard work
}

\author{
Farhan Zafar, MD, and David L. S. Morales, MD
}

From The Heart Institute, Cincinnati Children's Hospital Medical Center, Cincinnati, Ohio.

Disclosures: D.L.S.M. is a consultant for Berlin Heart, HeartWare, Azyio, CorMatrix, and SynCardia and is a member of the Adverse Events Committee for the Xeltis Xplore2 Food and Drug Administration trial. F.Z. has nothing to disclose with regard to commercial support.

Received for publication March 9, 2018; accepted for publication March 15, 2018.

Address for reprints: David L. S. Morales, MD, Cincinnati Children's Hospital Medical Center, Department of Cardiovascular Surgery, 333 Burnet Ave, MLC 2013, Cincinnati, OH 45229 (E-mail: david.morales@ cchmc.org).

J Thorac Cardiovasc Surg 2018;155:2602-3

$0022-5223 / \$ 36.00$

Copyright (C) 2017 by The American Association for Thoracic Surgery

https://doi.org/10.1016/j.jtcvs.2018.03.059

In this issue of the Journal, Bennink and colleagues ${ }^{2}$ present an investigation comparing the use of a synthetic bioabsorbable, polymer-based, pulmonary-valved conduit (Xeltis BV, Eindhoven, The Netherlands) with the use of a Hancock aortic-valved Dacron polyester fabric conduit (Medtronic Inc, Minneapolis, Minn) for pulmonary valve replacement in sheep. Their study demonstrated functional and morphologic changes in the polymer-based valves at 2 , 6, and 12 months. Although this is a limited preliminary study and presents some concerning findings at 12 months, there are several positive take-home points. There was "acceptable" valve function, neointima formation (nonthrombogenic), degradation of polymers (which may represent remodeling), deposition of native matrix, and lack of calcification out to 12 months. This study promotes a tissue-engineering approach toward the use of scaffolds (biologic or nonbiologic), allowing the native cells to populate the scaffold and lay down their own extracellular matrix along with resorption of the exogenous scaffold. This approach of in situ tissue engineering relies on the host response to the exogenous scaffold and the interplay between the immune and progenitor cells in the microenvironment provided by the scaffold, with additional influence from the hemodynamic environment. ${ }^{1}$ Although it is logistically (in terms cost and availability) superior to the traditional tissue-engineering approaches (cell based), in situ tissue engineering is still in its infancy and is fraught with occasional unexpected failures.

Bennink and colleagues ${ }^{2}$ showed tears and fragmentation of valve leaflets at 12 months, coinciding with shrinkage of the leaflet, rolling of the free edge, and associated progressive increase in regurgitation. The hemodynamic performance in these sheep appeared worse in all categories than with the Hancock conduit (limited to 24 weeks), with the Xeltis conduit having greater than mild insufficiency after 40 weeks. They demonstrated neointimal

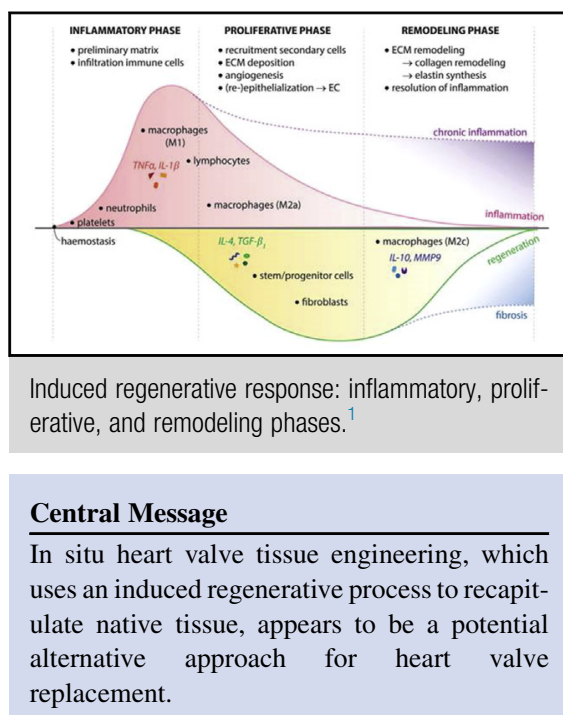

See Article page 2591. hyperplasia and thickening of the conduit wall and leaflet in some cases. ${ }^{2}$ These problems have also been noted in other studies examining in situ tissue engineering of heart valves $^{3-5}$ and are commonly attributed to 3 broad factors: (1) scaffold design (porosity, rate of degradation, etc), (2) hemodynamic environment (low vs high pressure, flow, shear stress, etc), and (3) cellular response (proinflammatory vs proregenerative, cell adhesion molecules, cell polarization and chemoattractive cytokines, etc). The process is not a static tissue formation but rather a functional tissue regeneration in continuously changing biomechanical microenvironments, ranging from initial acellular scaffold to degrading scaffold with variable matrix and cell infiltration. It is therefore extremely important to understand the fundamental reasons for failure in these devices and make adaptations to continue to make progress in this promising approach. Bennink and colleagues ${ }^{2}$ used a novel polycarpolactone- and polycarbonate-based supramolecular, ureido-pyrimidinone polymer. Ureido-pyrimidinone polymer is a unique polymer with high dimerization constant and hydrogen-binding motifs, resulting in tunable morphologies. ${ }^{6}$ Similar design changes, such as reducing fiber diameters to minimize blood activation, increasing pore size to promote cell infiltration, and modulating degradation rates to be compatible with extracellular matrix resorption, have been proposed by others. ${ }^{1}$ Changing fiber 
arrangements in the arterial versus the ventricular side to account for flow and shear stress differences, supplementing scaffolds with vascular endothelial growth factor (promoting angiogenesis) and interleukin 10 (promoting macrophage polarization to M2) are some other considerations being investigated.

We are far from a robust clinically applicable device that we can claim will remodel into native tissue. In situ tissue engineering of heart valves appears promising and appealing because it is based on creating the environment in which nature can do the hard work of valve creation.

\section{References}

1. Wissing TB, Bonito V, Bouten CV, Smits AI. Biomaterial-driven in situ cardiovascular tissue engineering — a multi-disciplinary perspective. NPJ Regen Med. 2017;2:18.
2. Bennink G, Torii S, Brugmans M, Cox M, Svanidze O, Ladich E, et al. A novel restorative pulmonary valved conduit in a chronic sheep model: mid-term hemodynamic function and histologic assessment. J Thorac Cardiovasc Surg. 2018; 155:2591-601.e3.

3. Driessen-Mol A, Emmert MY, Dijkman PE, Frese L, Sanders B, Weber B, et al. Transcatheter implantation of homologous "off-the-shelf" tissue-engineered heart valves with self-repair capacity: long-term functionality and rapid in vivo remodeling in sheep. $J$ Am Coll Cardiol. 2014;63:1320-9.

4. Reimer J, Syedain Z, Haynie B, Lahti M, Berry J, Tranquillo R. Implantation of a tissue-engineered tubular heart valve in growing lambs. Ann Biomed Eng. 2017; 45:439-51.

5. Kluin J, Talacua H, Smits AI, Emmert MY, Brugmans MC, Fioretta ES, et al. In situ heart valve tissue engineering using a bioabsorbable elastomeric implantfrom material design to 12 months follow-up in sheep. Biomaterials. 2017;125: 101-17.

6. Appel WP, Portale G, Wisse E, Danker PY, Meijer EW. Aggregation of ureidopyrimidinone supramolecular thermoplastic elastomers into nanofibers: a kinetic analysis. Macromolecules. 2011;44:6776-84. 